\title{
PRÁTICA PEDAGÓGICA PARA O ENSINO DE GEOGRAFIA FÍSICA A PARTIR DA LITERATURA: PROPOSIÇÕES INTRODUTÓRIAS
}

\author{
Pedagogical practice for teaching physical geography from literature: introductory \\ proposals
}

Práctica pedagógica pala la enseñanza de la geografía física de la literatura: propuestas de introducción

*Mestranda do Programa de Pós-Graduação em Geografia da Universidade Estadual de Campinas (UNICAMP)-gabikdiasgeo@gmail.com

${ }^{* *}$ Professora do Programa de Pós-Graduação em Geografia da Universidade Federal de Pelotas (UFPel) lizcdias@gmail.com

Recebido em 20/10/2019. Aceito para publicação em 20/10/2019.

Versão online publicada em 10/11/2019 (http://seer.ufrgs.br/paraonde)

\section{Resumo:}

A proposta visa contribuir no que tange as pesquisas realizadas acerca do ensino de Geografia Física e Literatura e suas metodologias de ensino, focando no processo, além de mostrar as carências existentes no que tange essa temática, para assim motivar outras pesquisas a serem realizadas. Além disso, a metodologia conta com constante revisão de literatura para embasamento teórico a respeito das questões mais pertinentes abordadas, como os conceitos de currículo, políticas educacionais, Geografia Física com ênfase em temáticas físicas e ambientais e práticas pedagógicas para o Ensino de Geografia. Abordar a questão do Ensino de Geografia Física e temáticas ambientais é muito importante para a compreensão dos fenômenos físicos e ambientais presentes no espaço geográfico, e na escola é necessário que o ensino dessas temáticas seja de fato significativo. Como considerações da pesquisa, é entendido que a presente proposta é de tamanha importância não só ao Ensino de Geografia como também para a Geografia Física no âmbito escolar. Utilizar de linguagens alternativas como a Literatura pode potencializar o processo de ensino e aprendizagem dos alunos, seja em qual etapa escolar for, pois proporciona entendimentos de forma significativa e em conjunção com a realidade.

Palavras-chave:Prática Pedagógica. Ensino de Geografia Física. Literatura.

\begin{abstract}
:
The proposal aims to contribute with regard to the research conducted on the teaching of Physical Geography and Literature and its teaching methodologies, focusing on the process, and show the existing shortcomings regarding this theme, to motivate other research to be carried out. In addition, the methodology has a constant literature review for theoretical basis on the most pertinent issues addressed, such as curriculum concepts, educational policies, physical geography with emphasis on physical and environmental issues and pedagogical practices for the teaching of geography. Addressing the issue of Physical Geography Teaching and environmental themes is very important for the understanding of the physical and environmental phenomena present in the geographical space, and at school it is necessary that the teaching of these themes is indeed significant. As research considerations, it is understood that the present proposal is of such importance not only to the teaching of geography but also to physical geography in the school environment. Using alternative languages such as literature can enhance the process of teaching and learning of students, whatever the school stage is, as it provides understandings significantly and in
\end{abstract}


conjunction with reality.

Keywords:PedagogicalPractice. PhysicalGeographyteaching. Literature.

\begin{abstract}
Resumen:
La propuesta tiene como objetivo contribuir con respecto a la investigación realizada sobre la enseñanza de Geografía Física y Literatura y sus metodologías de enseñanza, centrándose en el proceso, y mostrar las deficiencias existentes con respecto a este tema, para motivar otras investigaciones que se llevarán a cabo. Además, la metodología tiene una revisión constante de la literatura sobre bases teóricas sobre los temas más relevantes abordados, tales como conceptos curriculares, políticas educativas, geografía física, con énfasis en cuestiones físicas y ambientales y prácticas pedagógicas para la enseñanza de la geografía. Abordar el tema de la enseñanza de la geografía física y los temas ambientales es muy importante para la comprensión de los fenómenos físicos y ambientales presentes en el espacio geográfico, y en la escuela es necesario que la enseñanza de estos temas sea realmente significativa. Como consideraciones de investigación, se entiende que la presente propuesta es tan importante no solo para la enseñanza de la geografía sino también para la geografía física en el entorno escolar. El uso de lenguajes alternativos como la literatura puede mejorar el proceso de enseñanza y aprendizaje de los estudiantes, cualquiera que sea la etapa escolar, ya que proporciona una comprensión significativa y en conjunción con la realidad.
\end{abstract}

Palabras-clave: Práctica pedagógica. Enseñanza de Geografía Física. Literatura.

\title{
1 Introdução
}

A presente proposta justifica-se na medida em que cresce a discussão da importância de se construir metodologias e práticas pedagógicas que abordem as temáticas físicas e ambientais da Geografia na educação básica, tendo como exemplo pesquisas focadas no ensino do conteúdo relevo, no qual aborda que

[...] o ensino do relevo se encontra numa inadequação cognitiva e, acredita-se, que a não concretização de aprendizagens a partir do vivido acaba comprometendo a complexificação conceitual, o trabalho com base na abstração reflexiva demandado nos anos subsequentes do ensino (ASCENÇÃO, 2016, p. 203).

Acreditando na potencialidade do uso das diversas linguagens, a Literatura assume papel importante nessa discursão, afinal, para muitos a Literatura serve como pressuposto para a afirmação de uma cultura, como também de uma nação. Além disso, é de interesse pessoal relacionar Geografia e Literatura em uma pesquisa científica, de modo a mostrar como essas duas temáticas podem ser trabalhadas em conjunto, possibilitando assim um conhecimento mais significativo aos alunos.

Para Castrogiovanni (2007, p. 43) a abordagem da linguagem geográfica:

Apresenta características que precisam ser consideradas, tanto quanto possível, como fonte de explicação para as dificuldades que os alunos possam vir a ter na sua compreensão, como para planejar movimentos pedagógicos que facilitem o processo interativo.

A respeito da discussão acerca da Geografia Escolar, Ascenção (2013, p. 129) reitera que

$\mathrm{Na}$ atualidade coloca-se à Geografia Escolar a função de construir, junto aos

ParaOnde!?, Porto Alegre, v.12 n.2, p.262-270, 2019.http://seer.ufrgs.br/paraonde

Edição Especial - III Colóquio de Pesquisadores em Geografia Física Ensino de Geografia 
alunos, um raciocínio espacial a partir de conceitos e competências da ciência de origem dessa disciplina. Esse raciocínio, ainda que demande o trânsito entre escalas, deve, sobretudo, contribuir para que o educando interprete seu espaço de vivência e se assuma produtor do espaço.

Essa pesquisa faz parte do Trabalho de Conclusão de Curso (TCC) da autora, portanto está em fase de desenvolvimento. A proposta visa contribuir no que tange as pesquisas realizadas acerca do ensino de Geografia Física e Literatura e suas metodologias de ensino, focando no processo, além de mostrar as carências existentes no que tange essa temática, para assim motivar outras pesquisas a serem realizadas. É importante para que haja uma melhor compreensão acerca do que está sendo pesquisado no âmbito da Geografia física e ambiental que seja compreendido a importância de utilizar dos conteúdos da Geografia Física amplamente relacionados com os aspectos sociais e outras linguagens, como o exemplo da Literatura.

Além disso, busca propor a realização de uma prática pedagógica que visa, além da contribuição na formação de professores, também a um aprendizado mais significativo aos alunos na educação básica, sendo socialmente muito importante a sua utilização no contexto brasileiro de ensino.

\title{
2 Desenvolvimento
}

A metodologia adotada para a pesquisa sobre ensino de Geografia Física e temáticas ambientais se baseia pesquisa qualitativa. Conforme Claval (1999) até meados dos anos 1950 os geógrafos adotavam uma perspectiva positivista/naturalista, não estudando a dimensão "psicológica" da cultura. O interesse voltava-se para os aspectos materiais da cultura, as técnicas, as paisagens e o gênero de vida. As representações e as experiências subjetivas dos lugares foram completamente esquecidas.

Além disso, a metodologia contará com constante revisão de literatura para embasamento teórico a respeito das questões mais pertinentes abordadas, como os conceitos de currículo, políticas educacionais, Geografia Física com ênfase em temáticas físico e ambientais e práticas pedagógicas para o Ensino de Geografia.

Tendo em vista a introdução de outras linguagens na educação, que surge a partir da união de diversas e diferenciadas vias de conhecimento sob a manutenção da tradição e regras da poesia popular proporcionando a transformação em uma linguagem de cunho didático-poético que pode ser adequada aos saberes geográficos de forma muito prazerosa, lúdica, facultado explicação e compreensão de fato. Segundo Freire:

\begin{abstract}
[...] a educação ou ação cultural para a libertação; em lugar de ser aquela alienante transferência de conhecimento, é o autêntico ato de conhecer, em que os educandos - também educadores - como consciência 'intencionada' ao mundo ou como corpos conscientes, se inserem com os educadores - educandos também - na busca de novos conhecimentos, como consequência do ato de reconhecer o conhecimento existente. (FREIRE, 1984, p. 99)
\end{abstract}

Sendo assim, é muito significativo e significante se trabalhar em sala de aula, possibilitando dinamizar, de forma sucinta e criativa, atividades que englobem diversos

ParaOnde!?, Porto Alegre, v.12 n.2, p.262-270, 2019.http://seer.ufrgs.br/paraonde Edição Especial - III Colóquio de Pesquisadores em Geografia Física Ensino de Geografia 
formatos de linguagem, nesse exemplo, através da prática pedagógicaproduzida com a Literatura.

\section{A compreensão da Literatura fica claro na abordagem:}

Um romance, um poema, um quadro, um trecho de música são indivíduos, isto é, seres em que não se pode distinguir a expressão do exprimido, cujo sentido só é acessível por um contato direto e que irradiam sua significação sem abandonar seu lugar temporal e espacial. É nesse sentido que nosso corpo é comparável à obra de arte. Ele é um nó de significações vivas e não a lei de certo número de termos co-variantes. (MERLEAU-PONTY, 2000, p. 162).

O processo iniciará com a revisão de literatura sobre os temas propostos e logo em seguida já iniciará o levantamento de dados, a partir dos anais do XIII ENPEG - Encontro Nacional de Prática de Ensino em Geografia, ocorrido no ano de 2017. A partir dos anais serão selecionados os artigos para posterior análise, a partir da palavra-chave Literatura. Logo após, serão selecionados somente os artigos realizados pelos pesquisadores que contemplem a análise da Geografia e Literatura.

Após essa seleção, será desenvolvida uma ficha de registro de dados, onde após cada artigo lido haverá uma ficha com diversas questões - tanto de natureza estatística, como o local onde está sendo desenvolvida a pesquisa e tipo de artigo - como de natureza teórica, onde será analisado em qual contexto a pesquisa se inclui, sendo interessante ter essas informações para qualificar o trabalho.

A partir dessa análise, será verificada a abordagem e o uso da Literatura nas escolas, o tipo de pesquisa que foi realizada (como por exemplo um levantamento de dados ou uma prática pedagógica) e quais foram os resultados ou efeitos dessas práticas para os alunos, focando na análise da Geografia Física e questões ambientais e como ocorre pesquisas nessas temáticas.

Após o levantamento desses dados, será feita a tabulação dos dados, que servirá para demonstrar quais conteúdos e obras literárias estão sendo trabalhados para assim poder estruturar o trabalho, visando contribuir no que tange a área do Ensino de Geografia em geral. Visto isso, se faz necessário compreender os conhecimentos que estão sendo mais trabalhados e os que não estão sendo tão trabalhados na escola para suprir de forma justa essas demandas ainda pertinentes atualmente.
Portanto, o ensino de Geografia Física e temáticas ambientais e a Literatura necessitam estar sempre lado a lado, para além de diminuir a lacuna presente no ensino dessas temáticas, buscar um maior alicerce na formação de professores (e especificadamente de Geografia) e o interesse nos alunos pela Geografia e sua ampla análise a respeito do espaço geográfico, objeto de análise pela ciência geográfica.

Abordar a questão do Ensino de Geografia Física e temáticas ambientais é muito importante para a compreensão dos fenômenos físicos e ambientais presentes no espaço geográfico, e na escola é necessário que o ensino dessas temáticas seja de fato significativo, visto que, conforme Ascenção (2009, p. 38),

Reconhece-se, assim, a existência de dualidades, de conflitos, talvez intrínsecos à natureza da ciência geográfica. Admitindo-se, pois, ser objeto dessa ciência o estudo das organizações espaciais por meio da espacialidade dos fenômenos,

ParaOnde!?, Porto Alegre, v.12 n.2, p.262-270, 2019.http://seer.ufrgs.br/paraonde Edição Especial - III Colóquio de Pesquisadores em Geografia Física Ensino de Geografia 
compreende-se ser inerente a esse objeto a consideração para estudos dessa ciência tanto os aspectos físicos, como os aspectos humanos, os quais compõem os espaços.

É compreendido que há dificuldades no processo de ensino aprendizagem na escola das temáticas físicas e ambientais presentes na ciência geográfica, sendo assim propor práticas pedagógicas que abranjam essas temáticas se torna essencialpara transformar essa demanda por metodologias que foquem no ensino dessas temáticas, visto que é um ato normativo dentro da Lei de Diretrizes e Bases (LDB), onde trata a respeito do incentivo e investimento obrigatório à docência.

Castellar (2017, p. 209) reitera que "a didática tem uma função importante no processo de ensino e aprendizagem dos estudantes em geral", sendo necessário que sejam aprimoradas práticas de ensino. Além disso, é emergido a necessidade de apontar possibilidades e caminhos para criar ideias e difundi-las no campo da Geografia, tendo como temas as linguagens que permitem o acesso à diferentes temáticas.

Ainda sobre a importância da educação básica e aprendizagem na escola de maneira significativa aos estudantes, Passini (2012, p. 42) também traz suas contribuições no sentido que "podemos considerar como dever da escola proporcionar as aprendizagens das noções espaciais ao desenvolvimento das potencialidades de ler o espaço e sua representação como meios de desenvolver a autonomia".

Feitosa, Moraes e Costa (2012) vão dizer que:

[...] Literatura e a Geografia, abrindo uma nova perspectiva no âmbito dageografia ao trazer para o centro de suas discussões as relações que o homemcria com seu entorno (o que entendemos por "espaço geográfico vivido"), destacando, dessa maneira, aspectos como afetividade, sentimento de pertença, intersubjetividade, imaginação e memória. (FEITOSA, MORAES E COSTA, 2012, p. 186).

Para isso, é necessário que a pesquisa se embase em autores que abordem tanto as questões curriculares para o entendimento da importância de estudos acerca do Currículo e do Ensino de Geografia, quanto de Geografia Física e temáticas ambientais, além de Literatura, para assim propor um caminho metodológico que analise todas as partes.

Com isso, percebe-se que o ensino de temáticas físicas e ambientais por parte da Geografia é muito mais intrínseco do que imagina-se, pois está em sua base como ciência o conhecimento de fenômenos naturais e sociais, que, em congregação, formam o espaço geográfico, pois de acordo com Mendonça (2001, p. 115),

A abordagem geográfica do ambiente transcende à desgastada discussão da dicotomia geografia física versus geografia humana, pois concebe a unidade do conhecimento geográfico como resultante da interação entre os diferentes elementos e fatores que compõem seu objeto de estudo.

Visto isso, o presente projeto visa identificar as metodologias e práticas utilizadas nos artigos, para assim classificar quais conteúdos e/ou temáticas ainda possuem demandas de projetos e oficinas voltadas à esses conhecimentos, pois

A educação preocupa-se, antes de mais nada, em capacitar as pessoas a adquirir

ParaOnde!?, Porto Alegre, v.12 n.2, p.262-270, 2019.http://seer.ufrgs.br/paraonde Edição Especial - III Colóquio de Pesquisadores em Geografia Física Ensino de Geografia 
conhecimento que as leve para além da experiência pessoal, e que elas provavelmente não poderiam adquirir se não fossem à escola ou à universidade. (YOUNG, 2014, p. 196)

É fundamental então, que haja um comprometimento para o ensino dessa abordagem, de forma significativa e realista aos alunos, para que assim possam compreender que esses fenômenos estudados fazem parte de seu cotidiano, podendo a Literatura contribuir muito para que essa relação de fato aconteçajuntamente com a Geografia, pois de acordo com Young (2016, p. 9),

[...] as disciplinas escolares - que definem o direito ao conhecimento poderoso para todos os alunos - respondem a regras acordadas entre os professores especialistas dessas disciplinas sobre o que é considerado conhecimento válido; tais critérios, que derivam do conhecimento pedagógico dos professores especialistas das disciplinas e das suas ligações com especialistas dos campos acadêmicos nas universidades, fornecem acesso ao "melhor" conhecimento que pode ser adquirido por alunos, em diferentes níveis, assegurando, portanto, a possibilidade de progressão.

Visto isso, é necessário que haja essa relação e o entendimento da importância da universidade estar presente constantemente na escola e vice-versa, pesquisando e fazendo a troca de conhecimentos presentes tanto na universidade (conhecimento científico) quanto na escola (conhecimento escolar).

Nessa perspectiva, pode-se compreender que utilizar da Literatura como uma linguagem alternativa para o ensino de Geografia Física não é somente uma prática pedagógica isolada, mas sim uma recontextualização do conhecimento. Assim, na teoria da recontextualização do conhecimento proposta por Bernstein (2003, p. 80),

Os campos oficiais de recontextualização são arenas para a construção, distribuição, reprodução e mudança de identidades pedagógicas. As identidades pedagógicas têm uma base social e uma carreira. A base social representa os princípios de ordem social e os desejos institucionalizados pelo Estado em seu sistema educacional. A carreira é moral, instruída e localizada. Uma identidade pedagógica, então, é a fixação de uma carreira em uma base social.

Assim sendo, é realizado mais do que somente um resultado de uma prática, mas sim a mudança de um conhecimento, se recontextualizando em seu novo contexto de prática, que é a escola e seus sujeitos formadores e transformadores do conhecimento. Dessa mesma forma, Mainardes (2010, p. 13), diz que através da recontextualização "o discurso se desloca do seu contexto original de produção para outro contexto onde é modificado [...] e relacionado com outros discursos e depois é relocado". Percebe-se, assim, que a prática proposta futuramente não só transforma como cria conhecimentos através das práticas pedagógicas desenvolvidas no contexto escolar. aborda que

Pensando no diálogo da Geografia com a Literatura, Santos (2012, p. 276-277), o diálogo da geografia com a literatura apresenta-se polissêmico; uma relação que se (re)faz dentro dos limites e intencionalidades do pesquisador/leitor que se propõe a tal investida analítica. Percebe-se que a interpretação independe do gênero ou do fato literário analisado. É de interesse romper monólogos discursivos interpretativos, em que o discurso geográfico apenas "invente" maneiras de enriquecimento estético literário, ou seja, a literatura utilizada apenas como

ParaOnde!?, Porto Alegre, v.12 n.2, p.262-270, 2019.http://seer.ufrgs.br/paraonde Edição Especial - III Colóquio de Pesquisadores em Geografia Física Ensino de Geografia 
busca/invenção/construção do "belo" discursivo, isto, por si só, já soa como vazio e sem sentido para o entendimento das formas de imaginações (político, econômico, cultural, ideológico, filosófico etc.) espaciais e temporais.

Dessa forma, entende-se como é importante entrelaçar a Geografia com a Literatura, de modo que haja um sentido na proposta, e não somente usando da Literatura sem mostrar a sua importância. Atualmente, o trabalho com a interdisciplinaridade tem se mostrado de extrema relevância no meio acadêmico, já que intenta buscar um dialogo mais amplo ao interrelacionar áreas afins no intuito de entender e interpretar o mundo em plena transformação.

Concordando com Feitosa (2012, p. 192),

$\mathrm{Na}$ medida em que a Literatura e a Geografia se entrelaçam para refletir acerca dos traços simbólicos, subjetivos e intersubjetivos que compõem a essência dos relacionamentos das personagens com os espaços intensamente vividos, constatamos que as fronteiras do conhecimento cada vez mais tem sido superadas.

Dessa forma, entende-se que o presente trabalho tem como propósito intensificar e motivar pesquisas de cunho educacional que utilizem metodologias a partir do uso de diferentes linguagens, como a Literatura.

\section{Considerações finais}

Como considerações da pesquisa, é entendido que a presente proposta é de tamanha importância não só ao Ensino de Geografia como também para a Geografia Física no âmbito escolar. Utilizar de linguagens alternativas como a Literatura pode potencializar o processo de ensino e aprendizagem dos alunos, seja em qual etapa escolar for, pois proporciona entendimentos de forma significativa e em conjunção com a realidade.

Dessa forma, o trabalho pretendeu fazer uma revisão bibliográfica acerca do tema e propor introdutórias proposições que trabalhem como um elo na Geografia, a fim de destituir lacunas que ainda podem vir a ocorrem no ensino de temáticas físicas e ambientais, tanto na escola como no ambiente acadêmico. Sendo assim, a proposta identificou autores e métodos que estão trabalhando em busca de um bem comum no que tange o ensino dessas temáticas, versando aos níveis de ensino propostos.

Mesmo que de maneira introdutória, é considerado que ocorram mais pesquisas que utilizem da Literatura como um meio a ser utilizado no processo de ensino e aprendizagem.

\section{Referências}

AFONSO, Anice E.; ARMOUND, Núbia B. Reflexões sobre o ensino de Geografia Física no Ensino Fundamental e Médio. 10ํㅡㄹ Entro Nacional de Prática de Ensino em

ParaOnde!?, Porto Alegre, v.12 n.2, p.262-270, 2019.http://seer.ufrgs.br/paraonde Edição Especial - III Colóquio de Pesquisadores em Geografia Física Ensino de Geografia 
Geografia, p. 1-10, 2009.

Anais do XIII Encontro Nacional de Prática de Ensino em Geografia [recurso eletrônico] : conhecimentos da Geografia: percursos de formação docente e práticas na educação básica / organizadores Valéria de Oliveira Roque Ascenção... [et al.]. - Belo Horizonte: IGC, 2017.

ASCENÇÃO, Valéria de Oliveira Roque. Os conhecimentos docentes e a abordagem do relevo e suas dinâmicas nos anos finais do Ensino Fundamental. 2009. $151 f$. Tese (Doutorado) - Programa de Pós-Graduação do Departamento de Geografia da Universidade Federal de Minas Gerais, Belo Horizonte, 2009.

ASCENÇÃO, Valéria de O. R. O conhecimento do conteúdo relevo: contribuições metodológicas. Geografia Ensino \& Pesquisa, v. 17, n. 1, Jan/Abr 2013.

ASCENÇÃO, Valéria de O. R.; VALADÃO, Roberto C. Tendências contemporâneas na aplicação do conhecimento geomorfológico da Educação Básica: a Escala sob perspectiva. Espaço Aberto, PPGG-UFRJ, v. 6, n. 1, p. 191-208, 2016.

BERNSTEIN, Basil. A pedagogização do conhecimento:estudos sobre a recontextualização. Cadernos de Pesquisa, n. 120, p. 75-110, novembro 2003.

BRASIL. Presidência da República, Casa Civil. Lei № 12.796, de 4 de abril de 2013. Dispõe sobre a formação dos profissionais da educação e dá outras providências. Brasília: Presidência da República: 2013(b). Disponível em: <http://www.planalto.gov.br/ccivil_03/_ato2011-2014/2013/lei/l12796.htm> Acesso em 28 fev. 2018.

CALLAI, Helena Copetti. A Geografia no Ensino Médio. Revista Terra Livre. São Paulo, no 14, p. 60-99, Jan-Jul/1999.

CASTELLAR, S. Cartografia escolar e o pensamento espacial fortalecendo o conhecimento geográfico. In: Revista Brasileira de Educação em Geografia, Campinas, v. 7, no 13 , p. 207-232, jan./jun., 2017.

CASTROGIOVANNI, A. C. Geografia - Práticas Pedagógicas para o Ensino Médio. / organizado por Nelson Rego, Antonio Carlos Castrogiovanni e Nestor André Kaercher Artmed Editora S.A., 2007. p. 43.

CLAVAL, Paul. - Geografia Cultural. Florianópolis, EDUSC, 1999.

FEITOSA, Márcia M. Miguel; MORAES, Cláudia L. Gonçalves; COSTA, Janete de Jesus Serra. O ENTRELAÇAMENTO DE FIOS ENTRE A GEOGRAFIA E A LITERATURA: A CONSTRUÇÃO DE UM SABER MÚLTIPLO. Revista NUPEM, Campo Mourão, v. 4, n. 6, jan./jul. 2012.

FREIRE, Paulo, Educação e Mudança. Rio de Janeiro: Paz e Terra, 1984. 77p.

LESTEGÁS, Francisco Rodríguez. Concebir la geografia escolar desde uma nueva perspectiva: uma disciplina al servicio de la cultura escolar. Boletín de la A. G. E. n. 33, p. 173-186, 2002.

LOPES, Alice Casimiro. Política de Currículo: Recontextualização e Hibridismo. Currículo Sem Fronteiras, v. 5, n. 2, p. 50-64, Jul/Dez 2005.

LOPES, Alice Casimiro; MACEDO, Elizabeth. Currículo. In: Teorias de Currículo. São Paulo: Cortez, 2011. Apoio: FAPERJ.

ParaOnde!?, Porto Alegre, v.12 n.2, p.262-270, 2019.http://seer.ufrgs.br/paraonde Edição Especial - III Colóquio de Pesquisadores em Geografia Física Ensino de Geografia 
MAINARDES, Jefferson; STREMEL, Silvana. A teoria de Basil Bernstein e algumas de suas contribuições para as pesquisas sobre políticas educacionais e curriculares. Revista Telas, v. 11, n. 22, p. 1-24, Mai/Ago 2010.

MENDONÇA, Francisco de Assis. Geografia Socioambiental. Revista Terra Livre. São Paulo, no 16, p. 113-132, 1ำ semestre/2001.

MERLEAU-PONTY, M. Fenomenologia da percepção. 2. ed. São Paulo: Martins Fontes, 1999. $662 \mathrm{p}$.

OLIVEIRA, Marcus Aurélio Taborda de. Os estudos históricos sobre o currículo e as disciplinas escolares: das preocupações com as práticas escolares para o mundo da pesquisa acadêmica. Pensar a Educação em Revista, Curitiba/Belo Horizonte, v. 3, n. 1, p. 3-41, Jan/Mar 2017.

RIBEIRO, Priscila Campos. Produção de currículo: a escola e seus sujeitos. Espaço do Currículo, v. 4, n. 2, p. 197-208, setembro de 2011 a março de 2012.

SACRISTÁN, José Gimeno. O que significa o currículo? Saberes e incertezas sobre o currículo. Editora Penso.

SANTOS, Robinson Pinheiro. Resenha MARANDOLA Jr. Eduardo; GRATÃO, Lúcia Helena Batista (Orgs.). Geografia e literatura: ensaios sobre geograficidade, poética e imaginação. Londrina: EDUEL, 2010. 354 p. In: Revista Ateliê Geográfico, Goiânia/GO, v. 6 , n. 1 , p. $270-277, a b r / 2012$.

SILVA, Lidiane. R. C. et al. Pesquisa documental: alternativa investigativa na formação docente. In: IX Congresso Nacional de Educação - EDUCERE, III Encontro Sul Brasileiro de Psicopedagogia, 2009, p. 4554-4566, Curitiba.

YOUNG, Michael. Teoria do currículo:o que é e por que é importante. Cadernos de Pesquisa, v. 44, n. 151, p. 190-202, Jan/Mar 2004.

YOUNG, Michael. Por que o conhecimento é importante para as escolas do século XXI?Cadernos de Pesquisa, v. 46, n. 159, p. 18-37, Jan/Mar 2016. 